\title{
O ATENDIMENTO EDUCACIONAL ESPECIALIZADO E A ORGANIZAÇÃO DA SALA DE RECURSOS MULTIFUNCIONAIS: QUE TERRITÓRIO É ESSE? ${ }^{37}$
}

\author{
Glaura Braga ${ }^{38}$ \\ Rosana Prado 39 \\ Osilene $\mathrm{Cruz}^{40}$
}

\section{Resumo}

Este artigo é uma pesquisa bibliográfica com objetivo de abordar a educação inclusiva e as estruturas oferecidas pelas escolas para o acolhimento à diversidade. $O$ suporte teórico-metodológico é baseado em documentos legais, que embasam as políticas públicas de educação, além de estudos de Padilha (2007), Piovesan (2008), Meireles (2010), Pintor (2017), entre outros. Mais especificamente, apresenta um panorama sobre o Atendimento Educacional Especializado (AEE) no bojo da Política Nacional de Educação Especial na perspectiva da Educação Inclusiva e discute a proposta de efetivação das Salas de Recursos Multifuncionais relativa aos espaços, funções, atuação do profissional e público-alvo, refletindo sobre o território da educação especial concebido nas escolas regulares.

Palavras-chave: Educação Inclusiva. Atendimento Educacional Especializado.

\section{SPECIALIZED EDUCATIONAL SERVICE AND THE ORGANIZATION OF MULTI-FUNCTIONAL RESOURCE CLASSROOMS: WHAT IS THIS TERRITORY?}

\begin{abstract}
This paper is a bibliographical research and aims at reflecting on the theme of inclusive education and the structures offered by schools to deal with diversity. The theoreticalmethodological support is based on legal documents, related to public education policies, as well as studies promoted by Padilha (2007), Piovesan (2008), Meireles (2010), Pintor (2017), among others. More specifically, the research presents an overview of the role of the Specialized Educational Service (AEE) within the perspective of the National Policy on Special Education, related to Inclusive Education. We also discuss the proposal of Multi-functional Resource Classrooms implementation, considering the special education context in regular schools.
\end{abstract}

Key-words: Inclusive Education. Specialized Educational Service.

\footnotetext{
${ }^{37}$ Este estudo é parte integrante de dissertação de mestrado profissional em diversidade e inclusão desenvolvido na Universidade Federal Fluminense.

${ }^{38}$ Graduada em Pedagogia-UERJ, Pós-graduação em Psicopedagogia no Cotidiano Escolar pela UFF, Mestranda do CMPDI-UFF glaurabraga@gmail.com (21) 986770181

${ }^{39}$ Doutora em Educação pela Universidade Federal Fluminense, Professora Adjunta do Ensino Superior Bilíngue do Instituto Nacional de Educação de Surdos/INES. Membro permanente do CMPDI/UFF. rosanaprado.ines@gmail.com (21)999620110

${ }^{40}$ Doutora em Linguística aplicada e estudos da linguagem, Professora Adjunta do Ensino Superior Bilíngue do Instituto Nacional de Educação de Surdos/INES. Membro permanente do CMPDI/UFF. osilenesacruz@gmail.com (21) 979469322
} 


\section{Introdução}

A educação inclusiva vem sendo afirmada pela legislação brasileira, visando uma formação pautada em princípios de igualdade, solidariedade e equidade, de modo a reconhecer a diferença como parte do todo. Essa nova concepção sugere uma nova escola, aberta para todos os alunos, que carregam em sua singularidade as marcas de sua história e cultura. Nesse contexto, o lugar chamado escola, território social e de interação, precisa reconhecer o desafio posto, que é educar todos sem discriminação, respeitando a diversidade que se faz presente no dia a dia. As ações são acionadas por mudanças e o reconhecimento da diversidade entre os sujeitos impulsiona a busca por conquista de direitos e pela efetivação dos deveres.

A consolidação da democracia só será possível se houver garantia da equidade de condições para todos os cidadãos e se o espaço escolar for pensado como um local pertencente de todos. Nessa perspectiva, pensamos que:

O território não é apenas o conjunto dos sistemas naturais e de sistemas de coisas superpostas. O território tem que ser entendido como o território usado, não o território em si. O território usado é o chão mais a identidade. A identidade é o sentimento de pertencer àquilo que nos pertence. $O$ território é o fundamento do trabalho, 0 lugar da residência, das trocas materiais e espirituais e do exercício da vida (SANTOS, 2014, P.17)

Sendo assim, é necessário pensar em como a escola vem se estruturando para receber os alunos em situação de deficiência e como os alunos têm tido oportunidade de usar e se sentirem parte desse espaço. Atualmente, considerando a universalização do acesso à educação, a escola passou a receber alunos que não se enquadravam no processo de ensino vigente e as situações tanto de inclusão como exclusão se tornaram evidentes. Segundo Piovesan (2008):

Se o combate à discriminação é medida emergencial à implementação do direito à igualdade, todavia, por si só, é medida insuficiente. Faz-se necessário combinar a proibição da discriminação com políticas compensatórias que acelerem a igualdade enquanto processo. Isto é, para assegurar a igualdade não basta apenas proibir a discriminação, mediante legislação repressiva. São essenciais as estratégias promocionais capazes de estimular a inserção e inclusão de grupos socialmente vulneráveis nos espaços sociais. Com efeito, a 
igualdade e a discriminação pairam sob o binômio inclusão/exclusão (PIOVESAN, 2008, p. 4)

A sociedade tem o poder de desconstruir o perfil de uma educação que em sua história se caracterizou pela exclusão. E a escola desempenha um papel importante, não apenas ao aceitar as diferenças, mas na construção de conhecimentos e no exercício de uma prática que se contraponha à exclusão, enquanto promotora de reflexão e formadora do indivíduo democrático. A universalização dos direitos pela via da legislação, de certa forma, encaminhou para um olhar inclusivo, como diz Meireles (2014, p.85), que "Uma vez que só faz sentido produzir conhecimento e manter escolas se o nosso objetivo for empreender esforços para realizar uma educação que possibilite a justiça social.". Por isso, torna-se importante compreender as políticas de inclusão e seu processo de conquista na configuração de uma escola inclusiva.

O recebimento dos alunos com necessidades especiais em escolas regulares está demarcado desde a Constituição de 1988, como afirma a Nota Técnica № $42 / 2015$.

Ampara-se na Constituição Federal de 1988 que define em seu artigo 205 a educação como direito de todos, dever do Estado e da família, visando ao pleno desenvolvimento da pessoa, seu preparo para o exercício da cidadania e sua qualificação para o trabalho, garantindo, no artigo 208 , o direito ao atendimento educacional especializado $(2015$, p.1).

É evidente o apelo para um olhar diferenciado no que se refere ao acolhimento de todos os alunos nas escolas e ao direito ao atendimento educacional especializado ${ }^{41}$ até os dias atuais e muitas ações e políticas públicas têm permeado esse processo. Em termos legais e oficiais, a Sala de Recursos Multifuncionais/SRMs cumpre o propósito da organização de espaços, na própria escola comum, dotados de equipamentos, recursos de acessibilidade e materiais pedagógicos que auxiliam na

\footnotetext{
${ }^{41}$ Neste artigo consideraremos atendimento educacional especializado (com letras minúsculas) para todo atendimento específico direcionado aos alunos com Necessidade Educacionais Especiais/NEE, de maneira genérica. $O$ termo Atendimento Educacional Especial/AEE será grafado com letras maiúsculas ou por meio da sigla AEE, quando se referir à política pública de educação inclusiva, específica, instituída como principal orientação para o atendimento à diversidade nas escolas regulares afirmada no PARECER CNE/CEB 17/2001.
} 
promoção da escolarização, eliminando barreiras que impedem a plena participação dos estudantes público-alvo da educação especial, com autonomia e independência, no ambiente educacional e social (BRASIL, 2012).

A Sala de Recursos se caracteriza por um "espaço" destinado à educação especial, na escola pública regular, que havia sido prevista e inserida na estrutura do ensino para as escolas brasileiras no Plano Nacional de Educação (PNEE, 1977-1979) e pelo Centro Nacional de Educação Especial/CENESP, primeiro órgão oficial criado em 1973 para organizar a educação especial no território nacional (Pintor, 2015). Então, podemos observar que o Estado já buscava encaminhar, por meio de políticas públicas, o compromisso de efetivar a educação e de garantir o Atendimento Educacional Especializado/AEE, que tem como referência o território estipulado como Sala de Recursos Multifuncionais.

Vale ressaltar que o Brasil segue acordos firmados com a Organização das Nações Unidas (ONU, UNESCO), também com o Banco Mundial, com metas que preveem escolas para todos. Desde 1990, o governo federal vem, por meio de medidas legais, implantando uma política de inclusão escolar, mas muitas situações ainda estão em processo para a conquista da educação de qualidade para todos. Percebe-se, ainda, a presença de muitas crianças fadadas ao fracasso escolar, por questões econômicas e circunstanciais, provocadas pelo próprio ambiente que permitiu o acesso da criança na escola, mas que, diante da diversidade ${ }^{42}$ e das diferenças culturais, não impediu a existência de preconceito e discriminação, precisando essa criança adaptar-se à cultura imposta como correta pela educação. Assim, muitas famílias/responsáveis continuam tendo seus direitos negligenciados pela educação e as escolas, em sua maioria, ainda não dispõem de estruturas físicas e humanas capazes de garantir o acolhimento de todos com equidade.

A necessidade de avançar com ações que efetivem a inclusão social é latente em nossa sociedade. Segundo Pintor (2017, p.47), “A inclusão social e educacional,

\footnotetext{
${ }^{42} \mathrm{~A}$ diversidade se refere à multiplicidade de diferenças individuais na sociedade e na escola. Esta se constitui como um microcosmo da sociedade em que estão presentes indivíduos diferentes entre si em aspectos étnico-raciais, linguísticos, religiosos; em aspectos socioeconômicos e em condições de funcionamento físico, emocional, intelectual, entre outras características. (Pintor, 2017, p.45)
} 
dessa forma, se constitui como imperativo das atuais políticas públicas, buscando garantir o direito de ser, de estar, de aprender e de conviver, pilares da educação para este novo milênio". O processo de mudanças educacionais envolve toda a sociedade, pois exige um novo olhar, um ser humano que se identifique nos direitos e deveres junto ao outro. Para tanto, se faz necessário mudanças na estrutura do ensino tornando a escola um espaço democrático, de modo a garantir a todos os alunos sua permanência e apropriação do conhecimento. Nessa perspectiva, a educação propõe uma nova cultura escolar envolvendo a formação dos indivíduos para uma sociedade mais humana (BRAGA, 2018).

Este artigo caracteriza-se como uma pesquisa bibliográfica, cujo conteúdo é parte dos estudos realizados durante o curso de Mestrado Profissional em Diversidade e Inclusão (CMPDI/UFF). O objetivo é refletir sobre o papel do Atendimento Educacional Especializado no bojo das orientações da Política Nacional de Educação Especial na perspectiva da Educação Inclusiva, com o intuito de compreender a proposta e efetivação das Salas de Recursos Multifuncionais no que se refere aos espaços, à funcionalidade, à atuação do profissional e ao público alvo a que se destina.

Quando nos propomos a compreender o AEE como uma política pública de educação, estamos considerando que precisamos refletir sobre as mudanças sociais e a diversidade presente no cotidiano escolar, que exigem estratégias e recursos diferenciados para o atendimento à diversidade. É com esse propósito que iniciamos nossa pesquisa bibliográfica, refletindo sobre as políticas de educação especial e os desafios dos professores no âmbito do AEE.

\section{O AEE na Política Educacional do Brasil: Avanços e possibilidades}

As escolas têm vivido tempos de desafios e de lutas. Sinais de mudança desse cenário têm sido observados, com o aumento do percentual de alunos com deficiência, transtornos globais do desenvolvimento ou altas habilidades, incluídos em classe comum, passando de 71,7\% em 2013 para 86,8\% em 2017, de acordo com o Censo Escolar MEC/INEP (2017). Embora o número de alunos tenha crescido, os desafios vão além da matrícula com enfrentamentos de um cotidiano escolar que ainda não 
efetivou as modificações básicas relativas às questões físicas, arquitetônicas, metodológicas, tecnológicas e atitudinais.

Com o crescimento das matrículas de alunos com necessidades especiais em escolas regulares, intensificou-se a necessidade e a responsabilidade atribuída ao serviço instituído como AEE. Ao falarmos do serviço de AEE e do espaço específico de Salas de Recursos Multifuncionais, somos levados a refletir sobre a instituição desse território como "lugar específico" da educação especial dentro da escola regular. 0 fato de admitimos a necessidade de uma referência de educação especial no interior da escola regular, por meio de um espaço rotulado como próprio da educação especial, nos leva a questionar se esse espaço não deveria ser toda a escola.

Se o aluno em situação de deficiência precisa estar na escola, assim como todos os outros, por que a necessidade de um espaço destacado como lugar de trabalho complementar ou suplementar? Não deveria ser a sala de aula e a escola como um todo, esse espaço de excelência para o trabalho com todo e qualquer aluno? Se as Salas de Recursos Multifuncionais são espaços equipados com materiais e recursos específicos necessários ao atendimento desses alunos, por que não contar com esses recursos em sala de aula regular?

O avanço na conquista de direitos dos alunos com necessidades educacionais especiais é resultado de um longo processo de articulações e desarticulações políticas e econômicas que estruturam a sociedade. Portanto, não é possível conceber as políticas públicas de inclusão desvinculadas de uma sociedade capitalista estruturada para atingir melhores resultados, mais competentes e mais bem sucedidos. Assim, um processo de inclusão educacional vem provocar mudança, não simplesmente no que se refere às barreiras arquitetônicas, mas, principalmente, no que se refere ao projeto que uma sociedade tem para si mesma. De acordo com Brasil (2015a):

No paradigma da inclusão, à sociedade cabe promover as condições de acessibilidade necessárias a fim de possibilitar às pessoas com deficiência viverem de forma independente e participarem plenamente de todos os aspectos da vida. Nesse contexto, a educação inclusiva torna-se um direito inquestionável e incondicional (BRASIL, 2015a, p.11). 
O conceito de Educação Inclusiva está se formando e requer práticas de ensino que atendam às especificidades dos alunos em todos os níveis do ensino (MANTOAN, 2003). A Educação Especial como modalidade deve ser oferecida para todos os alunos que apresentam Necessidades Educacionais Especiais/NEE. Em 2001, as Diretrizes Nacionais para a Educação Especial na Educação Básica (CNE/CEB no2001) enfatizaram:

\begin{abstract}
Art. 2o Os sistemas de ensino devem matricular todos os alunos, cabendo às escolas organizar-se para o atendimento aos educandos com necessidades educacionais especiais, assegurando as condições necessárias para uma educação de qualidade para todos.

Art. 3ํ Por educação especial, modalidade da educação escolar, entende-se um processo educacional definido por uma proposta pedagógica que assegure recursos e serviços educacionais especiais, organizados institucionalmente para apoiar, complementar, suplementar e, em alguns casos, substituir os serviços educacionais comuns, de modo a garantir a educação escolar e promover o desenvolvimento das potencialidades dos educandos que apresentam necessidades educacionais especiais, em todas as etapas e modalidades da educação básica.
\end{abstract}

No entanto, para que isso aconteça, são necessárias mudanças na estrutura do ensino, tornando a escola um espaço democrático, um espaço de inclusão e diversidade, de maneira que todos os alunos tenham garantidos o acesso, a permanência, apropriação do conhecimento e oportunidades de interação social.

O Governo Federal, no período 2001 a 2008, traçou metas para incentivar e garantir a efetividade da política de educação inclusiva. Vale destacar também o Programa Educação Inclusiva Direito à Diversidade (BRASIL, 2005), ao propor:

Direito à diversidade, com vistas a apoiar a transformação dos sistemas de ensino em sistemas educacionais inclusivos, promovendo um amplo processo de formação de gestores e educadores nos municípios brasileiros para a garantia do direito de acesso de todos à escolarização, à oferta do atendimento educacional especializado e à garantia da acessibilidade (BRASIL, 2005, p.11)

Esse programa inclui pontos importantes sobre a organização, o recebimento e acolhimento dos alunos. Além disso, disponibiliza aos municípios-polo e secretarias estaduais de educação equipamentos, mobiliários e material pedagógico para a implantação de Salas de Recursos Multifuncionais/SRMs destinadas ao AEE, com vistas 
a apoiar o processo de inclusão educacional dos alunos em situação de deficiência na rede pública de ensino.

A preocupação com o atendimento de todos os indivíduos, independente de suas diferenças, se torna responsabilidade de todas as áreas de ensino, além de envolver gestores e educadores por meio de formação continuada implementada pelo MEC, organizada pelos polos de trabalho, caracterizando um marco importante para a mudança na educação brasileira, que passaria a entender a educação especial não mais como uma "educação diferente da educação regular", mas sim como uma modalidade de ensino que deve dialogar com todas as esferas educativas.

Dessa maneira, o acesso à educação para os alunos em situação de deficiência tornou-se mais dinâmico, contínuo e com possibilidades de atingir todos os níveis, etapas e modalidades de ensino. A inclusão do aluno em classes regulares provocou a necessidade de envolvimento dos gestores, professores e todos os que constituem o ambiente escolar, além de contar com o apoio do AEE e com o programa de formação para os gestores, configurando um marco importante para assegurar o sistema educacional inclusivo.

A formação de gestores e educadores marca um ponto de mudança no novo paradigma de escola inclusiva. As práticas educacionais precisam ser repensadas a partir do aluno em questão. O movimento envolve o professor, o currículo, a gestão redefinindo a compreensão a cerca das condições de infraestrutura escolar e dos recursos pedagógicos fundamentados da concepção de desenho universal ${ }^{43}$ (BRASIL, 2015b, p.11).

Ao usar o termo desenho universal no Documento Orientações para Implementação da Política de Educação Especial na Perspectiva da Educação Inclusiva (Brasil, 2015a), é proposto buscar um referencial que possibilite amplitude de acessibilidade cognitiva e fundamente princípios baseados em modelos práticos para

\footnotetext{
${ }^{43}$ A origem do termo Design Universal para Aprendizagem (UDL) é geralmente atribuída a David Rose, Anne Meyer e colegas do Centro de Tecnologia Especial Aplicada (CAST). O conceito de Desenho Universal se desenvolveu entre os profissionais da área de arquitetura na Universidade da Carolina do Norte - EUA, com o objetivo de definir um projeto de produtos e ambientes para ser usado por todos, na sua máxima extensão possível, sem necessidade de adaptação ou projeto especializado para pessoas com deficiência.
} 
oportunizar a aprendizagem para todos os estudantes. Rose e Meyer (2002) argumentam que o desenho universal:

[...] é um conjunto de princípios baseados na pesquisa e constitui um modelo prático para maximizar as oportunidades de aprendizagem para todos os estudantes. Os princípios do Desenho Universal se baseiam na pesquisa do cérebro e mídia para ajudar educadores a atingir todos os estudantes a partir da adoção de objetivos de aprendizagem adequados, escolhendo e desenvolvendo materiais e métodos eficientes, e desenvolvendo modos justos e acurados para avaliar o progresso dos estudantes (Rose e Meyer (2002), apud CAST, 2011, s.p.).

Nesse sentido, o princípio de desenho universal vem ampliar o olhar das escolas e dos educadores para as diversas oportunidades de espaços, recursos e estratégias que podem ampliar as possibilidades de aprendizagem dos alunos. Sobre essas possibilidades, O Decreto $n^{\circ} 5.296 / 2004$ apresenta o Desenho Universal como sendo

Concepção de espaços, artefatos e produtos que visam atender simultaneamente todas as pessoas, com diferentes características antropométricas e sensoriais, de forma autônoma, segura e confortável, constituindo-se nos elementos ou soluções que compõem a acessibilidade (BRASIL, 2004).

O conceito veio da arquitetura que buscava projetar os espaços públicos de maneira que o acesso fosse para todos, com autonomia e sem limitação para uso dos objetos e lugares. O conceito se estendeu para os processos de ensino-aprendizagem, em que educadores têm possibilidades de criar estratégias para abranger e envolver todos os estudantes. A afirmativa da lei traz a concepção do desenho universal como recurso pedagógico que coloca em pauta o papel arquitetônico com mudanças nos espaços mais acessíveis, nos objetos, tornando-os mais funcionais, oportunizando a participação das pessoas com deficiência em diversos espaços da sociedade. Ao refletir sobre os espaços escolares, apoiamo-nos em Viñao Frago e Escolano (2001, p.26-27), ao afirmarem que:

O espaço da escola não é apenas um continente em que se acha a educação institucional, isto é, um cenário planificado, a partir dos pressupostos exclusivamente formais no qual se situam os atores que intervêm no processo de ensino-aprendizagem para executar um 
repertório de ações. A arquitetura escolar é também, por si mesma, um programa, uma espécie de discurso que institui na sua materialidade um sistema de valores, como os de ordem, disciplina e vigilância, marcos para a aprendizagem sensorial e motora de toda uma semiologia que cobre diferentes símbolos estéticos, culturais e também ideológicos. No quadro das modernas teorias da percepção, o espaço-escola é, além disso, um mediador cultural em relação à gênese e à formação dos primeiros esquemas cognitivos e motores, ou seja, um elemento significativo do currículo, uma fonte de experiência e aprendizagem. A arquitetura pode ser considerada uma forma silenciosa de ensino (VIÑAO FRAGO e ESCOLANO, 2001, p.2627).

Esse conceito nos faz refletir sobre a importância de as políticas públicas direcionarem investimentos e recursos que tornem acessíveis diferentes espaços de convívio para as pessoas com necessidades especiais, mas que esses espaços também possam ser pensados a partir de um novo olhar para com as diferenças. A maneira como os espaços são pensados traduzem a concepção de escola proposta por um sistema ou por uma política nacional. Tornar os locais acessíveis e as possibilitar aprendizagens significa muito mais do que cumprir a lei ou oferecer acesso, mas, principalmente, indica a concepção de ensino considerada ao pensar o espaço proposto. Somente por meio de uma mudança conceitual e atitudinal serão possíveis novos acessos, não somente a espaços, mas também ao conhecimento, à autonomia e à vida constituída em sociedade.

Avançando nas considerações a respeito da legislação que apoia e legitima a educação na perspectiva inclusiva, em 2007, após o Brasil ter sido signatário da Convenção da Organização das Nações Unidas sobre os Direitos das Pessoas com Deficiência, em Nova York, foi assinado o Decreto n.o 6.253 (BRASIL, 2007), que instituiu e definiu o Atendimento Educacional Especializado/AEE, como sendo “(...) um conjunto de atividades, recursos pedagógicos e de acessibilidade, prestados de forma complementar ou suplementar à formação dos alunos no Ensino Regular".

Mais adiante, o Decreto no 6.57I (BRASIL, 2008) acrescentou um dispositivo à legislação anterior. O AEE passou a poder ser oferecido nas instituições públicas de ensino ou pelas instituições comunitárias, confessionais ou filantrópicas sem fins lucrativos, com a atuação exclusiva na educação especial, conveniadas com o poder público. Esse decreto dispõe sobre o AEE e regulamenta o parágrafo único do artigo 60 
da Lei de Diretrizes e Bases da Educação Nacional (LDBEN) no 9.394 (BRASIL, 1996), sendo considerada uma nova visão da Educação Especial e uma das condições para o sucesso da inclusão escolar dos alunos com deficiência. Segundo Miranda (2011, p.96), "Este atendimento existe para que os alunos possam aprender o que é diferente do currículo do ensino comum e que é necessário para que possam ultrapassar as barreiras impostas pela deficiência".

Outros documentos legais normatizaram e regulamentaram o direito da pessoa em situação de deficiência e o atendimento educacional especializado, como a Convenção Internacional sobre Direitos das Pessoas com Deficiência, conhecida como Declaração da Organização das Nações Unidas (ONU), aprovada pela Câmara de Deputados em 13 de maio de 2008, como emenda constitucional. E, seguindo os princípios dessa Declaração, foi editada a Política Nacional e Educação Especial na Perspectiva da Educação Inclusiva (Brasil, 2008a).

Em 2011, o Decreto no 7.611 (BRASIL, 2011) revogou o Decreto no 6.571 (BRASIL, 2008) e estabeleceu nos artigos 3 으 e 4 으 os objetivos do Atendimento Educacional Especializado (AEE), a seguir:

Art. 3o São objetivos do atendimento educacional especializado:

I - prover condições de acesso, participação e aprendizagem no ensino regular e garantir serviços de apoio especializados de acordo com as necessidades individuais dos estudantes;

II - garantir a transversalidade das ações da educação especial no ensino regular;

III - fomentar o desenvolvimento de recursos didáticos e pedagógicos que eliminem as barreiras no processo de ensino e aprendizagem; e IV - assegurar condições para a continuidade de estudos nos demais níveis, etapas e modalidades de ensino.

Art. 40 O Poder Público estimulará o acesso ao atendimento educacional especializado de forma complementar ou suplementar ao ensino regular, assegurando a dupla matrícula nos termos do art. 9o-a, do Decreto no 6.253, de 13 de novembro de 2007.

Assim, percebe-se que o decreto continuou afirmando o AEE como condição e principal estratégia para o atendimento às necessidades especiais dos alunos nas escolas. A garantia do acesso aos alunos em situação de deficiência em todos os níveis de escolarização tornou-se mais um passo para o enfretamento das diferenças diante das deficiências e abriu 
caminhos para novas oportunidades no desenvolvimento do ensino, precisando de investimentos do poder público para que haja equidade nos atendimentos.

O Decreto no 7.611/2011 instituiu a política pública de financiamento no âmbito do Fundo de Manutenção e Desenvolvimento da Educação Básica e de Valorização dos Profissionais da Educação - FUNDEB. O financiamento da dupla matrícula de estudantes, público-alvo da educação especial na educação básica, foi instituído no âmbito do FUNDEB, de modo a fomentar a organização e oferta do Atendimento Educacional Especializado na Perspectiva da Educação Inclusiva conforme disposto no artigo 6ㅇ:

Art. 60 Admitir-se-á, a partir de 10 de janeiro de 2010, para efeito da distribuição de recursos do FUNDEB, o cômputo das matrículas dos alunos da educação regular da rede pública que recebem atendimento educacional especializado, sem prejuízo do cômputo dessas matrículas na educação básica regular (BRASIL, 2008b).

Estabelecendo o duplo cômputo das matrículas dos estudantes com deficiência, transtornos globais do desenvolvimento e altas habilidades/superdotação, a dupla matrícula implica a contabilização do estudante tanto na educação regular da rede pública quanto no Atendimento Educacional Especializado. Visando ao desenvolvimento inclusivo dos sistemas públicos de ensino, esse decreto também define o AEE complementar ou suplementar à escolarização e os demais serviços da educação especial, além de outras medidas de apoio à inclusão escolar.

A Resolução no 4, que instituiu as Diretrizes Operacionais do Atendimento Educacional Especializado na Educação Básica, modalidade da Educação Especial (Brasil, 2009), também salientou sobre a necessidade de o AEE ser integrado ao Projeto Político Pedagógico (PPP) da escola, a importância de envolver a família e ser realizado em articulação com as demais políticas públicas. A oferta desse atendimento deve ser institucionalizada, prevendo na sua organização a implantação da SRM, a elaboração do plano de AEE, professores para o exercício da docência no AEE, demais profissionais como tradutor e intérprete da Língua Brasileira de Sinais, guiaintérprete e aqueles que atuam em atividades de apoio.

O documento PNEE-PEI (2008) aprovou a matrícula dos alunos com necessidades especiais no ensino regular, em que a política do AEE foi considerada eixo principal, orientando os sistemas de ensino a promover respostas às necessidades educacionais, garantindo: 
Transversalidade da educação especial desde a educação infantil até a educação superior;

Atendimento educacional especializado; Continuidade da escolarização nos níveis mais elevados do ensino;

Formação de professores para o atendimento educacional especializado e demais profissionais da educação para a inclusão escolar;

Participação da família e da comunidade;

Acessibilidade urbanística, arquitetônica, nos mobiliários e equipamentos, nos transportes, na comunicação e informação; e

Articulação intersetorial na implementação das políticas públicas (BRASIL, 2008, p.14).

Conforme os documentos, o desafio posto à Educação Especial é funcionar como uma modalidade de ensino transversal em todos os níveis, etapas e modalidades, preferencialmente, na rede regular de ensino. A Educação Especial deve promover o $A E E$, disponibilizando recursos e serviços, além de orientar quanto a sua utilização no processo de ensino e aprendizagem nas turmas comuns do ensino regular (BRASIL, 2008a). Sua atuação se dá de maneira complementar ou suplementar ao sistema regular de ensino, possibilitando ao indivíduo, com atendimento do AEE, a inclusão na Educação Básica e continuidade dos estudos até o Ensino Superior, com oportunidades de aprendizagem de acordo com suas especificidades e potencialidades.

O AEE foi pensando para que os alunos possam constituir turmas regulares, contando com o apoio pedagógico dos professores do AEE para identificarem, organizarem e elaborarem materiais pedagógicos necessários ao atendimento das necessidades diante do contexto educacional, além de orientar e acompanhar todo o processo de ensino e aprendizagem dos alunos público-alvo desse atendimento.

Em relação aos níveis de ensino, a PNEE-EI (2008) define que o AEE seja ofertado na Educação Infantil, incluindo os serviços de estimulação precoce, na etapa da escolaridade obrigatória, no turno inverso ao da classe comum, na própria escola ou centro especializado que realize esse serviço educacional, na modalidade de Educação de Jovens e Adultos e educação profissional, na Educação Indígena, do campo e quilombola, na Educação Superior, envolvendo ações de planejamento e organização de recursos e serviços para a promoção da acessibilidade arquitetônica, nas comunicações, nos sistemas de informação, nos materiais didáticos e pedagógicos e no desenvolvimento de todas as atividades que envolvam o ensino, a pesquisa e a extensão (BRASIL, 2008a, p. 10-12). 
O trabalho desenvolvido pelo AEE não se apresenta, em nenhum momento, como substitutivo ao trabalho do ensino regular, mas as ações são desenvolvidas para que o aluno receba condições de se desenvolver, levando em conta o princípio de igualdade. No entanto, é importante lembrar que o professor de AEE não é o único responsável pedagógico por todas as ações que promovem o aprendizado dos alunos em situação de deficiências, transtornos globais do desenvolvimento ou altas habilidades e superdotação. O professor regente, a coordenação pedagógica, a gestão escolar e os demais componentes da escola estão envolvidos e igualmente responsabilizados pelo processo de inclusão educacional desses alunos. Para além das responsabilidades destinadas aos educadores, destacamos também a responsabilidade governamental em promover condições de efetivação de atendimento aos alunos.

O art. 3ㅇ do Decreto no 6.571 (BRASIL, 2008b), revogado pelo Decreto n $^{\circ} 7611 / 2011$, especifica que o Ministério da Educação prestará apoio técnico e financeiro às seguintes ações voltadas à oferta do $\mathrm{AEE}$, incluindo a implantação de salas de recursos multifuncionais, a formação continuada de professores para o atendimento educacional especializado, de gestores, educadores e demais profissionais da escola para a educação inclusiva, a adequação arquitetônica de prédios escolares para acessibilidade, a elaboração, produção e distribuição de recursos educacionais para a acessibilidade e estruturação de núcleos de acessibilidade nas instituições federais de educação superior (BRASIL, 2008b, p. 01).

A Resolução n-4/2009, do Conselho Nacional de Educação, da Câmara de Educação Básica (BRASIL, 2009), institui Diretrizes Operacionais para o AEE na Educação Básica, modalidade Educação Especial e, no artigo 2ํㅡㄹ esclarece que a função do AEE é "complementar ou suplementar a formação do aluno por meio da disponibilização de serviços, recursos de acessibilidade e estratégias que eliminem as barreiras para sua plena participação à sociedade $e$ desenvolvimento de sua aprendizagem. " O AEE, então, se destina a garantir a permanência do aluno na escola regular, promovendo primeiro o acesso ao currículo, por meio de acessibilidade física, como adaptações arquitetônicas, à oferta de transporte, adequação de mobiliário e de equipamentos, acesso a sistemas de comunicação. Dado o acesso, como consequência, para o ensino em si, o AEE tem como finalidade, também, favorecer a organização de materiais didáticos e pedagógicos, estratégias diferenciadas, instrumentos de avaliação adequados às 
necessidades do aluno para que, de fato, sua permanência na escola proporcione desenvolvimento acadêmico e pessoal.

De acordo com o documento de Orientação para implementação da Educação Especial na Perspectiva da Educação Inclusiva (2015), é fundamental a construção de políticas de formação, financiamento e gestão, necessárias para a transformação da estrutura educacional, a fim de assegurar as condições de acesso, participação e aprendizagem de todos os estudantes, concebendo a escola como um espaço que reconhece e valoriza as diferenças.

\section{As Salas de Recursos Multifuncionais: conceituação e especificidades}

As Salas de Recursos Multifuncionais (SRMs) foram implementadas para oferta do AEE, por meio do Programa de "Implantação de Salas de Recursos Multifuncionais", com o objetivo de apoiar os sistemas públicos de ensino na sua organização e oferta do AEE de maneira a contribuir para o fortalecimento do processo de Inclusão Escolar nas classes comuns de ensino. Tais salas são espaços organizados e constituídos por equipamentos de informática, auxílio técnico, materiais pedagógicos e mobiliários adaptados, para atendimento às necessidades educacionais especiais dos alunos (BRASIL, 2007).

Para promover a implantação desse serviço, o MEC disponibilizou o Manual de Orientação: Programa de Implantação de Sala de Recursos Multifuncionais contendo os objetivos e as ações, os critérios para implantação, a adesão, o cadastro e a indicação das escolas, a composição das salas e a orientação para aquisição de recursos materiais e tecnológicos (BRASIL, 2010).

As SRMs foram disponibilizadas para os estados e municípios, delegando-se aos gestores dos sistemas de ensino a responsabilidade de indicar as escolas a serem contempladas, conforme sua demanda e de acordo com os critérios estabelecidos pelo programa. A entrega e a instalação dos equipamentos são monitoradas pelo MEC. As orientações a respeito da organização e funcionamento da SRM foram estabelecidas, principalmente por meio das legislações: Decreto no 6.571/2008, Resolução no 4/2009, 
Parecer no 13/2009, Nota Técnica nำ11/2011, Decreto no 7.611/2011 e de documentos como o Manual de Orientação: Programa de Implantação de Sala de Recursos Multifuncionais (2010) e o Documento Orientador Programa Implantação Salas de Recursos Multifuncionais (2012).

Nessa perspectiva, o MEC explica sobre a concepção, a definição e a quem se destina o trabalho realizado pelo Atendimento Educacional Especializado nas Salas de Recursos Multifuncionais:

São espaços da escola onde se realiza o atendimento educacional especializado para alunos com necessidades educacionais especiais, por meio do desenvolvimento de estratégias de aprendizagem, centradas em um novo fazer pedagógico que favoreça a construção de conhecimentos pelos alunos, subsidiando-os para que desenvolvam o currículo e participem da vida escolar (MEC, 2006, p.13).

O serviço destinado ao AEE visa à escolarização dos alunos especiais, a sua participação na rotina escolar, a sua inserção no processo ensino e aprendizagem, de acordo com suas especificidades e pleno desenvolvimento cognitivo, social e acadêmico. $\mathrm{O}$ atendimento acontece em interface com o trabalho desenvolvido na sala de aula comum, no contraturno escolar, mas com interlocução entre os professores envolvidos. $O$ espaço físico foi pensado para atender a diversidade das demandas:

Um espaço organizado com materiais didáticos, pedagógicos, equipamentos e profissionais com formação para o atendimento às necessidades educacionais especiais (...) esse espaço pode ser utilizado para o atendimento das diversas necessidades educacionais especiais e para desenvolvimento das diferentes complementações ou suplementações curriculares (MEC, 2006, p.14).

O espaço deve ser organizado de modo a oferecer suporte às necessidades educacionais do seu público alvo, que são estudantes em situação de deficiência, transtornos globais do desenvolvimento e altas habilidades/superdotação, favorecendo o acesso ao conhecimento (BRASIL, 2008).

Vale ressaltar que a matrícula do aluno em situação de deficiência no AEE é condicionada à matrícula no ensino regular. Esse atendimento pode ser oferecido em Centros de Atendimento Educacional Especializado da rede pública ou privada sem fins lucrativos. Tais centros devem estar de acordo com as orientações da PNEE-PEI (2008a) e com as Diretrizes Operacionais da Educação Especial para o Atendimento 
Educacional Especializado na Educação Básica (MEC/SEESP, 2009). Os professores responsáveis pelos atendimentos dos alunos em Salas de Recursos Multifuncionais deverão seguir as diretrizes previstas no documento publicado pela Secretaria de Educação Especial (MEC/SEESP, 2009)

$O$ atendimento no AEE deve considerar as especificidades dos alunos com necessidades especiais, no que se refere aos ritmos e estilos diversos de aprendizagem, além de desenvolver a autonomia, facilitar o processo de inclusão por meio dos recursos pedagógicos e de acessibilidade. É importante desenvolver uma dinâmica de trabalho condizente com as potencialidades desses indivíduos, promovendo desenvolvimento de habilidades que potencializarão o aprendizado na sala de aula inclusiva. O AEE poderá ser realizado em atendimentos individuais ou em grupos, de acordo com as necessidades dos alunos.

A atuação no AEE precisa de um caráter interativo e interdisciplinar. Para tanto, deve haver acompanhamento do trabalho na turma regular, em concomitância com os da sala de recursos e também nos centros de atendimento, nos núcleos de acessibilidade das instituições superiores, nas classes hospitalares, para oferta de serviços e recursos de educação especial (BRASIL, 2008a).

Todos os programas e ações do governo federal em relação aos estados e municípios e Distrito Federal pressupõem um regime de colaboração que distribui responsabilidades a cada sistema de ensino no que se refere ao Programa Implantação Salas de Recursos Multifuncionais (BRASIL, 2010). O MEC assegura as seguintes ações sob suas responsabilidades, tais como a aquisição de recursos para as salas; disponibilização das salas e critérios adotados; o acompanhamento da entrega dos materiais $\mathrm{n}$ escolas; orientação e sistemas de ensino; cadastro das escolas com recursos multifuncionais; formação continuada de professores para o AEE; encaminhamento, assinatura e publicação dos Contratos de Doação; dualização dos recursos das salas implantadas pelo Programa e apoio à acessibilidade.

Essas e outras ações estão sendo implementadas por meio de políticas públicas, legislações e programas de atendimento à diversidade nas escolas. Sobre essa temática da inclusão, pesquisas como as de Flogli (2010), Meireles (2010; 2014) e Miranda (2011) apontam para a importância das ações que se traduzem no cotidiano 
escolar, no fazer pedagógico de todos os dias e nas possibilidades de viver experiências com a diversidade.

Apesar de a legislação e as políticas públicas afirmarem o direito dos alunos de estarem nas escolas públicas regulares, sabemos que muitos são os enfrentamentos para que as condições se efetivem, devido a várias questões: o governo não garante todos os recursos necessários, as escolas ainda não apresentam experiência histórica com a inclusão, os profissionais estão em processo de formação contínua e os desafios aparecem cotidianamente.

O fazer pedagógico se constrói a cada dia, teorias e práticas se somam na busca pelo acolhimento à diversidade e o AEE se insere nesse processo como território de referência da educação especial na escola regular. Assim, pensamos que a organização do AEE é relevante para o processo de Inclusão Educacional, sendo necessário lançar mão de vários recursos: físicos, humanos e pedagógicos, instrumentos para que os alunos com deficiência, TGDs e altas habilidades e superdotação possam ter acesso ao currículo como forma de garantia de aprendizagem.

Conforme informações disponibilizadas no documento MEC/SECADI/2013, foram implantadas 4.000 salas, totalizando 41.801 Salas de Recursos Multifuncionais em nível nacional, de 2005 a 2013. O Programa de Implantação de Salas de Recursos Multifuncionais (MEC, 2013, p. 09), instituído pelo MEC/SECADI por meio da Portaria Ministerial no 13/2007, integra o Plano de Desenvolvimento da Educação - PDE e o Plano Nacional dos Direitos da Pessoa com Deficiência - Viver sem Limite e objetiva:

a) Apoiar a organização da educação especial na perspectiva da educação inclusiva;

b) Assegurar o pleno acesso dos estudantes público alvo da educação especial no ensino regular em igualdade de condições com os demais estudantes;

c) Disponibilizar recursos pedagógicos e de acessibilidade às escolas regulares da rede pública de ensino;

d) Promover o desenvolvimento profissional e a participação da comunidade escolar.

Para atingir tais objetivos, o MEC (SECADI, 2013) realiza as seguintes ações:

a) Aquisição dos recursos que compõem as salas; 
b) Informação sobre a disponibilização das salas e critérios adotados;

c) Monitoramento da entrega e instalação dos itens às escolas;

d) Orientação aos sistemas de ensino para a organização e oferta do AEE;

e) Cadastro das escolas com sala de recursos multifuncionais implantadas;

f) Promoção da formação continuada de professores para atuação no AEE;

g) Publicação dos termos de Doação;

h) Atualização das salas de recursos multifuncionais implantadas pelo Programa;

i) Apoio financeiro, por meio do PDDE Escola Acessível, para adequação arquitetônica, tendo em vista a promoção de acessibilidade nas escolas, com salas implantadas. (MEC, 2013, p. 0910)

Aos gestores dos sistemas de ensino cabe definir quanto à implantação das salas de recursos multifuncionais, o planejamento da oferta do AEE e a indicação das escolas a serem contempladas, conforme as demandas da rede, atendendo os seguintes critérios do Programa:

- A secretaria de educação a qual se vincula a escola deve ter elaborado o Plano de Ações Articuladas - PAR, registrando as demandas do sistema de ensino com base no diagnóstico da realidade educacional;

- A escola indicada deve ser da rede pública de ensino regular, conforme registro no Censo Escolar MEC/INEP (escola comum);

- A escola de ensino regular deve ter matrícula de aluno(s) público alvo da educação especial em classe comum, registrado(s) no Censo Escolar/INEP, para a implantação da sala Tipo I;

- A escola de ensino regular deve ter matrícula de aluno(s) cego(s) em classe comum, registrado(s) no Censo Escolar/INEP, para a implantação da sala de Tipo Il;

- A escola deve ter disponibilidade de espaço físico para o funcionamento da sala e professor para atuação no AEE. (BRASIL, 2012)

O governo, por meio de ações direcionadas às escolas e às secretarias de educação, procura organizar a implantação de novas salas de recursos multifuncionais. Essas são ações articuladas entre o Censo, MEC e o INEP. No entanto, é importante lembrar a responsabilidade da gestão escolar em viabilizar não apenas o espaço ou o cadastramento da SRMs no MEC, mas também providenciar a verba escolar, os recursos comuns como materiais de papelaria, jogos didáticos, adaptação de materiais pedagógicos, entre outros. 
Conforme o documento do MEC (BRASIL, 2010), a composição das Salas de Recursos Multifuncionais visa a atender às demandas dos sistemas de ensino. A tipologia da sala é definida com base nos dados do Censo escolar, sendo classificadas como sala do tipo I e sala do tipo II, que serão apresentadas na próxima seção.

\section{Composição das Salas de Recursos Multifuncionais}

As SRMs são designadas por Tipo I e Tipo II, constituídas por equipamentos, mobiliário e materiais didáticos pedagógicos (Tipo I) e acrescidas de recursos e materiais didáticos pedagógicos específicos para a educação de alunos com cegueira e deficiência visual (Tipo II).

As Salas de Recursos Tipo I são constituídas pelos seguintes itens:

\begin{tabular}{|l|l|}
\hline Equipamentos & Materiais Didático/Pedagógico \\
\hline 02 Microcomputadores & 01 Material Dourado \\
\hline 01 Laptop & 01 Esquema Corporal \\
\hline 01 Estabilizador & 01 Bandinha Rítmica \\
\hline 01 Scanner & 01 Memória de Numerais I \\
\hline 01 Impressora laser & 01 Tapete Alfabético Encaixado \\
\hline 01 Teclado com colméia & 01 Software Comunicação Alternativa \\
\hline 01 Acionador de pressão & 01 Sacolão Criativo Monta Tudo \\
\hline 01 Mouse com entrada para acionador & 01 Quebra Cabeças - seqüência lógica \\
\hline 01 Lupa eletrônica & 01 Dominó de Associação de Idéias \\
\hline Mobiliários & 01 Dominó de Frases \\
\hline 01 Mesa redonda & 01 Dominó de Animais em Libras \\
\hline 04 Cadeiras & 01 Dominó de Frutas em Libras \\
\hline 01 Mesa para impressora & 01 Dominó tátil \\
\hline 01 Armário & 01 Alfabeto Braille \\
\hline 01 Quadro branco & 01 Kit de lupas manuais \\
\hline 02 Mesas para computador & 01 Plano inclinado - suporte para leitura \\
\hline 02 Cadeiras & \\
\hline
\end{tabular}

Quadro 1- Composição de Salas de Recursos Multifuncionais Tipo 1. Fonte: SECADI (Portal MEC, 2012)

As Salas de Recursos Tipo II são constituídas por todos os recursos da sala tipo I, adicionados os recursos de acessibilidade para alunos com deficiência visual, conforme abaixo: 


\begin{tabular}{|l|}
\hline Equipamentos e Matérias Didático/Pedagógico \\
\hline 01 Impressora Braille - pequeno porte \\
\hline 01 Máquina de datilografia Braille \\
\hline 01 Reglete de Mesa \\
\hline 01 Punção \\
\hline 01 Soroban \\
\hline 01 Guia de Assinatura \\
\hline 01 Kit de Desenho Geométrico \\
\hline
\end{tabular}

Quadro 2- Composição de Salas de Recursos Multifuncionais Tipo 2 Fonte: SECADI (Portal MEC, 2012)

Tendo em vista as especificações apresentadas das respectivas salas, é necessário que as escolas públicas reservem espaços físicos para o funcionamento das SRMs, onde serão realizados os Atendimentos Educacionais Especializados - AEE. Elas possuem mobiliário, materiais didáticos e pedagógicos, recursos de acessibilidade e equipamentos específicos para o atendimento dos alunos público alvo da Educação Especial e que necessitam do AEE no contraturno escolar. A organização e a administração desse espaço são de responsabilidade da gestão escolar e o professor que atua nesse serviço educacional deve ter formação para o exercício do magistério de nível básico e conhecimentos específicos de Educação Especial, adquiridos em cursos de aperfeiçoamento e de especialização.

Ressaltamos que o atendimento oferecido nas SRMs pelo AEE não deve ser caracterizado como um ensino de reforço escolar, mas sim, uma proposta de Plano de AEE para complementar ou suplementar as atividades escolares. O plano de AEE serve como fundamentação para os planos de aula ou de atendimentos, nele estão contidas todas as metas e recursos que se pretendem utilizar para o atendimento individual do aluno. Deverá ser flexível de acordo com as necessidades específicas de cada sujeito, enfatizando o seu potencial e as suas condições de acesso à aprendizagem.

De acordo com o estabelecido no documento legal do MEC, o AEE "é um serviço da educação especial que identifica, elabora, e organiza recursos pedagógicos e de acessibilidade, que eliminem as barreiras para a plena participação dos alunos, considerando suas necessidades específicas" (SEESP/MEC, 2008). São exemplos práticos de AEE: o ensino da Língua Brasileira de Sinais (LIBRAS) e do código BRAILLE, a introdução e formação do aluno na utilização de recursos de tecnologia assistiva, como a comunicação alternativa e os recursos de acessibilidade ao computador, à orientação 
e mobilidade, a preparação e disponibilização ao aluno de material pedagógico acessível, entre outros.

\title{
O AEE e os enfrentamentos no cotidiano escolar inclusivo
}

A inclusão dos alunos em situação de deficiência em escolas regulares, historicamente, enfrentou barreiras e ainda hoje a segregação acontece no ambiente que deveria promover a inclusão. De acordo com Silva (2008, p.71),

\begin{abstract}
A inclusão é processo que vem sendo construído ao longo do tempo, variando conforme suas implicações e necessidades, e não estado. Não existe um estado de inclusão permanente. Toda inclusão é sempre temporária e precisa ser revista de maneira contínua para evitar que os processos e mecanismos de exclusão social retornem.
\end{abstract}

Assim, o trabalho desenvolvido pelos professores de sala de recursos não pode ser uma ação individual e nem tampouco esporádica, precisa fazer parte da filosofia escolar e estar presente no Projeto Político Pedagógico, concretizando-se tanto nas atitudes cotidianas, quanto nos planejamentos e organizações escolares continuamente.

A legislação favorece e determina a inclusão como um direito do cidadão, mas fazer parte do contexto escolar envolve mudanças de atitudes que vão além da disponibilidade do atendimento do AEE. As decisões que envolvem mudanças no desenho universal para o acolhimento e autonomia de todos precisam ser prioridade na gestão educacional e em toda a comunidade escolar.

Os gestores, professores e equipe de trabalho da escola devem ter como objetivo a inclusão e a aprendizagem de todos os alunos. Os alunos compõem a diversidade do ambiente e aqueles que estão em situação de deficiência têm particularidades que precisam ser pensadas para o seu melhor desenvolvimento. A questão é que muitas vezes, os educadores ${ }^{44}$ se apoiam no discurso do desconhecimento ou da falta de formação para não se permitirem viver experiências

\footnotetext{
${ }^{44}$ Quando usamos o termo educadores, estamos considerando que todos os profissionais da escola são profissionais da educação e, portanto, são agentes educadores.
} 
com a diferença. Lidar com o diferente e buscar estratégias não é fácil. É um desafio cotidiano que precisa ser enfrentado. Sobre esse processo, Salgado (2008, p.62) afirma:

\begin{abstract}
Construir e cultivar práticas de inclusão pressupõe, também, manterse motivado e envolvido para fazer a inclusão no dia a dia da sala de aula, não deixando que valores não inclusivos, como comodismo, elitismo, pessimismo entre tantos outros, afetem a forma de trabalhar e planejar do professor, evitando assim excluir os alunos que apresentam diferentes ritmos de aprendizagem. Mas não pensemos que construir e cultivar culturas, políticas e práticas de inclusão é uma tarefa fácil. Exige, antes de tudo, o exercício da capacidade de equilibrar-se sobre bases que não são sólidas e, portanto, não garantem a segurança e o sucesso tão desejado em qualquer prática profissional.
\end{abstract}

É grande o desafio de lidar com as diferenças em uma sociedade capitalista que valoriza os mais fortes e mais capazes. Por isso, é necessário inaugurar outra cultura social: uma cultura que compreenda as diferenças como constitutivas da humanidade e não como incapacidades. Mesmo diante da importância e da utilidade das SRMs, consideramos que ações inclusivas não podem se restringir ao atendimento nesse espaço de instrução e não pode ser um trabalho solitário, sem o apoio e parceria dos outros componentes da escola.

Percebemos que o processo de inclusão encontra muitas fragilidades e ainda permite a segregação. O atendimento educacional especializado em Sala de Recursos ainda é visto como "salvação" do aluno na escola inclusiva. Na maioria das vezes, o aluno frequenta esse atendimento duas ou três vezes por semana, em intervalos que podem ir de 30 minutos à uma hora, no contraturno. Propomos, diante disso, as perguntas: Esse tempo e frequência são suficientes e adequados para todos?; Se os atendimentos acontecem no contraturno, como acontece o contato entre professor de SRMs e professores regentes de sala de aula inclusiva?; De que maneira acontecem as trocas?; Como as ações poderão ser pensadas coletivamente? Além dessas questões, outras nos inquietam: Ensinar ou não os conteúdos? Estimular funções intelectivas ou ensinar atividades escolares que ele não consegue realizar em sala de aula? Adaptar as atividades e avaliações para os professores ou contribuir para que os professores façam as suas adaptações? 
As escolas e os educadores ainda não encontraram uma resposta única e talvez essa resposta nem exista. As demandas são diferentes em função das diversas realidades e a busca por respostas faz parte do processo. O tempo de atendimentos, os tipos de atividades desenvolvidas, interação entre professores, objetivos das propostas pedagógicas, os materiais precisam ser construídos de acordo com as demandas de cada aluno e cada realidade escolar, tendo em vista a necessidade de se constituir uma nova cultura escolar com valorização das diferenças e desejo de viver experiências.

É premente considerar as especificidades dos alunos frequentadores das SRMs e do tipo de AEE que seja adequado às peculiaridades desses discentes. Além disso, é preciso assumir o comprometimento com a educação inclusiva, respeitando-se as necessidades, por exemplo, observando se a SRM apresenta a estrutura com recursos materiais (tipo I ou tipo II) e humanos (profissional capacitado, consciente do seu papel e da sua importância no processo de ensino e aprendizagem do aluno).

Assim, entendemos que a SRM pode ser um território de referência para fomentar as reflexões e práticas pedagógicas inclusivas. Considerando que a escola, como um todo, ainda não tem experiência histórica com a inclusão, esse é o momento de inaugurar novas práticas. A educação inclusiva deve ser um compromisso de todos os componentes da escola, mas se precisa ser inaugurado, apoiado e orientado por um serviço específico, pensamos que o Atendimento Educacional Especializado possa cumprir esse papel necessário e de transição para a construção de um ambiente em que as diferenças possam se tornar gradativas e continuamente valorizadas como constitutivas dos seres humanos. Os limites humanos, sociais, econômicos e políticos farão parte da escola e dos serviços oferecidos por ela porque fazem parte de um contexto social mais amplo. No entanto, é necessário buscar respostas e acreditar no potencial humano, tanto para aprender, no caso dos alunos, como para mudar práticas e culturas, no caso da escola e dos que a constituem.

A escola, quando recebe o aluno em situação de deficiência, deve compreender que as suas possibilidades estão muito além do diagnóstico apresentado, que o trabalho realizado promove o desenvolvimento de novas habilidades e 
competências. Nessa perspectiva, deve motivar os pais sobre possíveis avanços e novas possibilidades, mesmo diante dos impedimentos causados pela deficiência.

Dessa maneira, pensamos que os espaços destinados para o AEE devem ser estendidos a toda escola e demais professores. A inclusão terá mais ganhos se não estiver direcionada, apenas, pela ação do professor de AEE. O trabalho deve ser um compromisso social, dos atores que movem o dia a dia da escola, pois muitas barreiras precisam ser enfrentadas para que a realidade de uma escola para todos com garantia de aprendizagem torne-se possível.

A partir das considerações teórico-metodológicas sobre educação inclusiva e, especificamente, a implantação de SRM para atender à demanda de alunos que necessitam de ações específicas para suas demandas, apresentamos a seguir as considerações finais do artigo, sem a pretensão de esgotar o assunto, mas com a consciência de termos apresentado um quadro sobre a temática abordada.

\section{Considerações finais}

Concluindo este artigo, procuramos destacar a temática do Atendimento Educacional Especializado e o espaço da Sala de Recursos Multifuncional, mostrando um panorama histórico no que se refere às legislações e políticas de educação inclusiva, descrevendo as estruturas propostas para alunos com necessidades educacionais especiais.

A nova realidade educacional inclusiva se depara com profissionais da educação em toda parte do país que devem estar preparados para conduzir o processo de ensino e aprendizagem para esse público, o qual ocupa um lugar em sala de aula e precisa ser visto como aprendiz em potencial, com direito a investimentos e estratégias que possibilitem seu desenvolvimento.

A democratização do acesso à escola trouxe o aumento do número de alunos e, consequentemente o aumento dos desafios sobre como ensinar diante da diversidade. Instalaram-se os questionamentos, as inquietações e a busca pelos possíveis caminhos e procedimentos necessários. Assim, o Sistema Educacional democratizou o acesso à escola, porém, ainda não conseguiu garantir o acesso ao 
saber para todos. A experiência com a inclusão é historicamente recente em nossa sociedade e a escola, apesar de buscar caminhos, ainda não encontrou uma direção para o aprendizado de todos, considerando as necessidades específicas.

Nossa reflexão destaca que, muitas vezes, os alunos em situação de deficiência ou que apresentam transtornos globais do desenvolvimento ou altas habilidades e superdotação precisam de um espaço e momentos específicos para trabalhos direcionados de maneira individual, que contemplem suas necessidades. A SRMs tem o potencial de ser este espaço e ainda fomentar as reflexões e práticas que valorizem a diversidade na escola.

Ao mesmo tempo, apresentamos nossa preocupação com o possível estigma dedicado ao serviço do $A E E$, no sentido de que a responsabilidade sobre as especificidades dos alunos possa se restringir ao professor de AEE e que se estimule o conceito de que todos os problemas possam ser solucionados dentro de uma Sala de Recurso Multifuncional, o que não é a verdade, pois a educação inclusiva diz respeito a todos os integrantes da comunidade escolar - pais, alunos, gestores, escola como um todo, buscando admitir e aceitar a diversidade.

Reconhecemos a importância e a necessidade do AEE e preocupamo-nos com a possibilidade dessa nova cultura escolar ser instalada de maneira equivocada sem o compartilhamento de experiências entre os diversos atores escolares. Dessa maneira, a escola precisa construir coletivamente as condições para atender as diversidades de seus alunos, independentemente de suas diferenças. Para tal, é necessário que se organizem, planejem e reestruturem práticas pedagógicas a favor da inclusão, reconhecendo as diferenças humanas como elementos que podem contribuir com o desenvolvimento e emancipação de todos. De acordo com Adorno (2006, p.170),

O talento não se encontra previamente configurado nos homens, mas que em seu desenvolvimento, ele depende do desafio a que cada um é submetido. Isto quer dizer que é possível "conferir talento" a alguém. A partir disso, a possibilidade de levar cada um a "aprender por intermédio da motivação" converte-se numa forma particular do desenvolvimento da emancipação.

Assim, acreditamos que o AEE e os profissionais que o empreendem possam ser os instigadores desse processo de desafiar tantos os alunos quanto os professores. 
E que esses aos serem provocados possam despertar seus "talentos" tanto no que se refere às múltiplas possibilidades de aprendizagem dos alunos, quanto às diversas capacidades de ensinar dos professores. É preciso fazer com que os professores acreditem em seu potencial para redescobrir a prática cotidiana, a partir de uma educação para emancipação. Adorno afirma (2006, p.170):

\footnotetext{
Isso não significa emancipação mediante a escola para todos, mas emancipação pela demolição da estrutura vigente em três níveis e por intermédio de uma oferta formativa bastante diferenciada e múltipla em todos os níveis, (...), possibilitando deste modo, o desenvolvimento da emancipação em cada indivíduo.
}

Uma escola inclusiva demanda indivíduos formados para a diversidade, mas essa formação deverá ser um processo empreendido ao longo de experiências que permitam experimentar novas estruturas e elaborações das relações sociais. Não basta que a escola seja "para todos", mas é necessário que todos possam viver experiências significativas e coletivas que possibilitem a emancipação do pensamento e da formação de todos.

As reflexões propostas neste trabalho, portanto, buscaram mostrar que a inclusão tem se tornado uma realidade, a partir de vários documentos legais e suas implementações implicam em provocações que ao questionar e desestabilizar as verdades estabelecidas, possam inaugurar reflexões e práticas voltadas para o potencial de cada ser humano e na possibilidade de viver experiências com a diversidade constitutiva da humanidade de cada um em particular e de todos em interação. Certamente, outras questões também importantes não foram exploradas neste trabalho, devido ao objetivo estabelecido e ao escopo da pesquisa. No entanto, acreditamos que este estudo tenha potencial para estimular problematizações que qualifiquem tantas outras experiências de educação nas escolas inclusivas.

\section{Referências}

ADORNO, T. W. Educação e emancipação. São Paulo, Paz e Terra, 2006.

ALVES, D.O. GOTTI, M.O. GRIBOSKI, C.M. DUTRA,C.P. Sala de Recursos Multifuncionais: espaços para atendimento educacional especializado. Brasília, Ministério da Educação, Secretaria de Educação Especial, 2006. 
BRAGA, G. C. O. Elaboração de um guia orientador para nortear as intervenções pedagógicas e organização do Atendimento Educacional Especializado nas Salas de Recursos Multifuncionais. In: COLOQUIO LUSO-BRASILEIRO DE EDUCAÇÃO-COLBEDUCA, 3, Portugal: Braga, 2018.

BRASIL. Ministério da Educação e Cultura. Secretaria Geral. Centro Nacional de Educação Especial. Plano Nacional de Educação Especial 1977/1979. Brasília, Departamento de Documentação e Divulgação, 1977. 31p.

Lei 9.394/96, de 20 de dezembro de 1996. Estabelece as diretrizes e bases da educação nacional. Diário Oficial da República Federativa do Brasil, Brasília, DF, 31 de dez.1996. Disponível em: http://www.planalto.gov.br/ccivil_03/Leis//9394.htm Acesso em 17 de fevereiro de 2018.

Ministério da Educação. Resolução CNE/CEB no 2, de 11 de setembro de 2001. Institui Diretrizes Nacionais para Educação Especial na Educação Básica/Secretaria de Educação Especial. Brasília, MEC/SEESP, 2001.

Disponível em: http://portal.mec.gov.br/cne/arquivos/pdf/CEB0201.pdf. Acesso em: 12 de fevereiro de 2018.

Ministério da Educação/Secretaria de Educação Especial. Programa de Capacitação de Recursos Humanos do Ensino Fundamental - Deficiência visual, vol. 1, Série Atualidades Pedagógicas 6. Brasília, MEC/SEESP, 2001.

Disponível em:

http://www.dominiopublico.gov.br/download/texto/me000463.pdf. Acesso em 14 de fevereiro de 2018.

Decreto № 5.296/2004 de 02 de dezembro de 2004. Brasília: MJ/SAJ, 2004. Disponível em: http://www.planalto.gov.br/ccivil_03/_ato2004-2006/2004/decreto/d5296.htm Acesso em 10 de fevereiro de 2018.

Revista Inclusão. Vol.1. 2005. Disponível em:

http://portal.mec.gov.br/seesp/arquivos/pdf/revistainclusao1.pdf. Acesso em: 10 de fevereiro de 2018.

Decreto № 6.253, de 13 de novembro de 2007. Dispõe sobre o Fundo de Manutenção e Desenvolvimento da Educação Básica e de Valorização dos Profissionais da Educação - FUNDEB, regulamenta a Lei no 11.494, de 20 de junho de 2007. Disponível em: http://www.planalto.gov.br/ccivil_03/_ato2007-2010/2007/decreto/d6253.htm Acesso em: 16 de fevereiro de 2018.

Portaria Normativa no- 13, de 24 de Abril DE 2007. Dispõe sobre a criação do Programa de Implantação de Salas de Recursos Multifuncionais. Diário Oficial da República Federativa do Brasil, Poder executivo, Brasília, 26 Abril de 2007. Disponível em: http://portal.mec.gov.br/index.php?option=com_docman\&view=download\&alias=9935-portaria-13-24abril-2007\&Itemid=30192 Acesso em: 10 de fevereiro de 2018.

Ministério da Educação. Política Nacional de Educação Especial na Perspectiva da Inclusão Escolar, 2008 a. Secretaria de Educação Especial. Disponível em: portal.mec.gov.br/seesp/arquivos/pdf/politica.pdf. Acesso: 10 de fevereiro de 2018.

Decreto no 6571, de 17 de setembro de 2008b. Revogado pelo Decreto no 7.611 , de 17 de novembro de 2011. Dispõe sobre o atendimento educacional especializado. Disponível em: http://www.planalto.gov.br/ccivil_03/_ato2007-2010/2008/decreto/d6571.htm Acesso em 10 de fevereiro de 2018. 
Ministério da Educação. Resolução no 4: Diretrizes Operacionais para o Atendimento Educacional Especializado na Educação Básica, modalidade Educação Especial. Brasília, 2009. Disponível em: http://portal.mec.gov.br/dmdocuments/rceb004_09.pdf Acesso em 20 de fevereiro de 2018.

Ministério da Educação. Nota Técnica no 11/2010, de 07 de maio de 2010b. Secretaria de Educação Especial. Orientações para a institucionalização da Oferta do Atendimento Educacional Especializado. Disponível em: <http://portal.mec.gov.br. Acesso em: 10 de fevereiro de 2018.

- Ministério da Educação Secretaria de Educação Continuada, Alfabetização, Diversidade e Inclusão/SECADI. Documento Orientador Programa Implantação de Salas de Recursos Multifuncionais. Disponível em:

http://portal.mec.gov.br/index.php?option=com_docman\&view=download\&alias=11037-docorientador-multifuncionais-pdf\&Itemid=30192 . Acesso em 14 de março de 2018.

Diretrizes Curriculares Nacionais Gerais da Educação Básica / Ministério da Educação. Secretaria de Educação Básica. Diretoria de Currículos e Educação Integral. MEC, SEB, DICEI. Brasília, 2013. Disponível em: http://portal.mec.gov.br/docman/julho-2013-pdf/13677-diretrizes-educacao-basica2013-pdf/file Acesso em 14 de março de 2018.

Orientação para implementação da Educação Especial na Perspectiva da Educação Inclusiva. 2015a. Disponível em:

http://portal.mec.gov.br/index.php?option=com_docman\&view=download\&alias=17237-secadidocumento-subsidiario-2015\&Itemid=30192 Acesso em: 15 de fevereiro de 2018.

Nota Técnica № 42. Orientação aos Sistemas de Ensino quanto à destinação dos materiais e equipamentos disponibilizados por meio do Programa Implantação de Salas de Recursos Multifuncionais. MEC / SECADI /DPEE , Brasília, 2015. Disponível em:

http://portal.mec.gov.br/index.php?option=com_docman\&view=download\&alias=17656-secadi-nt42orientacoes-aos-sistemas-de-ensino-sobre-destinacao-dos-itens-srm\&ltemid=30192 Acesso em 15 de fevereiro de 2018.

Censo Escolar da Educação Básica 2016. Notas Estatísticas. Ministério da Educação, INEP. Brasília, $2017 . \quad$ Disponível em: http://download.inep.gov.br/educacao_basica/censo_escolar/notas_estatisticas/2017/notas_estatistica s_censo_escolar_da_educacao_basica_2016.pdf Acesso em: 14 de março de 2018.

CAST. Design Universal para Aprendizagem. 2012. Redes cerebrais: reconhecimento, estratégico e afetivo (Meyer \& Rose, 1998; Rose \& Meyer, 2002) htttp://inclusaoeacessoastecnologiaspt.weebly.com/3---desenho-universal-na-prendizagem-udl.html. Acesso em: 15 de fevereiro.

FOGLI, B.F.C. dos S. A dialética da inclusão em educação: uma possibilidade em um cenário de contradições: Um estudo de caso sobre a implementação da política de inclusão para alunos com deficiências na rede de ensino Faetec. Universidade Estadual do Rio de Janeiro - UERJ, Rio de Janeiro, 2010.

MEIRELES, R. M. do P. L. Educação Bilíngue de alunos surdos: experiências inclusivas na Escola Municipal Paulo Freire, Niterói (RJ). Dissertação de Mestrado em Educação, Universidade Federal Fluminense, Niterói, 2010.

R. M. do P. L. Políticas de inclusão e práticas pedagógicas na educação de alunos surdos: Programa de Bilinguismo de Niterói/ RJ. Tese de doutorado em Educação, Universidade Federal Fluminense, Niterói, 2014. 
MIRANDA, T. G. O atendimento educacional especializado: AEE em sala de recursos. In: MIRANDA, T. G \& FILHO, T.A.G. (orgs.). Educação especial em contexto inclusivo: reflexão e ação. Salvador, EDUFBA,2011.

PINTOR, N. A. M. Uma Análise do projeto espaço integrado de desenvolvimento e estimulação (EIDE) na rede municipal de ensino de Niterói/RJ- Período 2008-2009. Tese de Doutorado em Saúde da Criança e da Mulher, Instituto Fernandes Figueira, Rio de Janeiro, 2011.

Educação inclusiva. Rio de Janeiro: SESES, 2017.

PIOVESAN, F. Ações afirmativas no Brasil: desafios e perspectivas. Estudos feministas. Florianópolis, JSTOR, 16 no 3, p. 887-896, setembro-dezembro,2008.

SANTOS, M. Territórios Educativos para Educação Integral. Série Cadernos Pedagógicos. PDE/ Programa Mais Educação, no12, Ministério da Educação, Brasília, 2014.

SALGADO, S.S. Inclusão e Processos de Formação. In: SANTOS, M.P. e PAULINO, M.M. Inclusão em Educação: culturas, políticas e práticas. São Paulo, Cortez, 2008.

SILVA, A.P. Inclusão e Processos de Formação. In: SANTOS, M.P. e PAULINO, M.M. Inclusão em Educação: culturas, políticas e práticas. São Paulo, Cortez, 2008.

VIÑAO FRAGO, A. \& ESCOLANO, A. Currículo, Espaço e Subjetividade. A arquitetura como programa. Rio de Janeiro: DP\&A, 2001, pp.26-27. Em 07/04/2018

Data de envio: 23 de abril de 2018

Data de aceite: 30 de junho de 2018 